\section{A new measure of semantic appraisal for studies of secondary rewards ${ }^{1}$}

KATHRYN K. RILEIGH and JUM C. NUNNALLY, Vanderbilt University, Nashville, Tenn. 37203

Forty elementary-school children learned to discriminate among four nonsense syllables, each associated with a different reward contingency: continuous reward, nonreward, neutrality, and loss of reward. Subsequently, two forms of a verbal-association measure were administered (each child receiving one form). The syllables were rated on items relating to four semantic scales: pleasantmess, understandability, curiosity, and goal-relatedness. The two forms yielded essentially the same results; relative to the neutral syllable, the rewarded syllable was rated more pleasant, more understandable, and more goal-related. The clear-cut nature of these results suggests that the new measure of semantic appraisal will be useful in many types of investigations of secondary rewards in humans.

Previous research (e.g., Nunnally, Duchnowski, \& Parker, 1965; Nunnally, Stevens, \& Hall, 1965) has demonstrated that objects of neutral value can become infused with rewarding properties through repeated association with primary rewards. By the same process, neutral objects associated with loss of reward tend to assume punishing properties. The effects of this learned, or secondary, reward value have been evidenced in various types of dependent measures. Secondary reward value has been evidenced by: (1) effects on visual attention (Nunnally, Duchnowski, \& Parker, 1965; Nunnally, Stevens, \& Hall, 1965; Parker \& Nunnally, 1966), (2) expectancies of future reward (Nunnally, Duchnowski, \& Parker, 1965; Parker \& Nunnally, 1966; Nunnally \& Faw, 1968), (3) ratings concerning the pleasantness of stimuli (Nunnally, Duchnowski, \& Parker, 1965; Nunnally, Stevens, \& Hall, 1965; Parker \& Nunnally, 1966; Kendall \& Nunnally, 1968; Nunnally \& Faw, 1968), and (4) choices among objects of value. 2

Although in the aforementioned investigations it has been established that secondary rewards have widespread effects on human behavior, semantic measures of evaluation have yielded the most consistent and striking results. One of the earlier semantic measures involved the assignment of positive and negative adjectives to the objects with conditioned values. It was found that positive evaluation was attributed to objects associated with rewards (Nunnally, Stevens, \& Hall, 1965). This technique was replaced by a "guess-who" game, which is more "projective" in nature. Statements involving positive, negative, and neutral activities were to be attributed to stick figures bearing, as names, nonsense syllables with acquired values. Objects associated with reward were consistently rated as more positive than either a neutral object or one associated with loss of reward (Nunnally, Duchnowski, \& Parker, 1965; Parker \& Nunnally, 1966; Nunnally, Duchnowski, \& Knott, 1967; Nunnally \& Faw, 1968).

Whereas the aforementioned measures of semantic appraisal have served themselves well in our previous studies of secondary rewards, they permitted us to measure only one dimension of meaning, namely, that of evaluation, or pleasantness. What is needed for studies of secondary rewards is a more general instrument, one that permits the measurement of other important dimensions of meaning in addition to evaluation. Our first attempt in that regard was to develop scales relating to "curiosity value;" this proved useful in differentiating among syllables that had been associated with different types of reward schedules (Kendall \& Nunnally, 1968).

Prior to the present investigation, items were constructed relating to four facets of meaning: pleasantness, understandability, curiosity, and goal-relatedness. The purpose of the investigation was to determine how sharply differently treated syllables would be differentiated by the new scales. An incidental aspect of the investigation was to determine the differences, if any, resulting from two methods of administering the scales. One method was a straightforward association test; the other method was more projective.

\section{SUBJECTS}

The Ss were 40 girls from fourth-, fifth-, and sixth-grade classes in the Metropolitan Nashville school system. ${ }^{3}$ The girls ranged in age from 10 to 12 years. The mean age of Ss was 10.7 years. The children were generally from lower-middle-class socio-economic backgrounds.

\section{APPARATUS}

\section{Stimuli}

Four CVC trigrams (MYV, TEJ, CEB, KIF) served as the stimuli. The nonsense syllables were partially counterbalanced in their roles as rewarded (W), non rewarded $(0)$, reward-loss $(L)$, and neutral $(N)$ stimuli in order to control for inherent preferences; complete counterbalancing was impossible due to the criterion selection procedure for Ss. The syllables remained constant in their roles for each $S$. The reward-loss syllable was one for which $\mathbf{S}$ was required to relinquish previously acquired rewards. The neutral syllable did not actually play a role in the task, but $S$ was familiarized with it. Learning Task

A discrimination apparatus was employed in the learning task. It consisted of two cups mounted in a board. Three lids, each bearing a card with one of the pertinent syllables $(W, 0, L)$ on it, were placed two at a time over the cups to result in a binary-choice situation on each trial. This apparatus has been described in detail by Nunnally \& Faw (1968).

\section{LEARNING PROCEDURE}

Each $S$ was seen individually in a research trailer. He was given the following instructions: "Today you are going to have a chance to earn some marbles which you can later trade for prizes [a prize table with many school supplies was shown to S]. This is how you can earn the marbles: Here are four lids, and each one has a different make-beljeve word on top [E and $S$ practiced pronouncing the syllables]. We are not going to use this one [N], so I will set it aside [within S's view]. On the bottom of each of these lids [W, $0, L]$ is one of these tickets [earn 2, blank, pay 2]. On each turn, I will set two of these lids out over the cups. You choose one of them and do what the ticket says Ithe consequences of the tickets were explained]. Remember, always try to choose a lid that will help you get marbles."

The $\mathrm{S}$ was not allowed to see which tickets were attached to which lids before the task began. $S$ was trained on the contingencies in four phases. Each of the syllables was presented with only one other during the first three phases (e.g., W-0, $\mathrm{W}-\mathrm{L}, \mathrm{L}-0$ ), then all three syllables were presented two at a time in the last phase. Each phase consisted of 15 left-right pairings of the syllables arranged in random order. In order to reach criterion on each phase, $S$ was required to make 10 consecutive correct choices. A correct choice was defined as maximizing gains (e.g., selecting $\mathrm{W}$ over 0,0 over $\mathrm{L}$, and $\mathrm{W}$ over L). After each choice, $S$ was allowed to see the ticket appearing under the alternate lid.

SEMANTIC APPRAISAL MEASURE

The 32-item measure was administered verbally to only those $S s$ who achieved 
criterion on all four phases of the learning task. Approximately $5 \%$ of the Ss failed to meet the criterion requirement. Each $S$ received one of three random orderings of the items approximately 2 days after conditioning. In addition, two forms of the measure were administered, each to a random half of the Ss. One form (word-form) consisted of asking $S$ to indicate which of the four syllables (printed on cards laid before him) made him think of each of the items. The other form (boy-form) employed stick-figure drawings of three identical boys, each having one of the four syllables printed as his name. $S$ indicated to which boy the items applied. Of necessity, the wording of items was changed slightly on the boy-form in order to make sense. The four scales of meaning represented and their items (for the word-form) follow.

Pleasantness Scale.

Positive: Something that is good to you; Something nice; Something that is kind; Something pleasant. Negative: Something that is unfriendly; Something unpleasant; Something you do not like; Something awful.

\section{Understandability Scale}

Positive: Something easy to figure out; Something that you know all about; Something that is easy to understand. Negative: Something puzzling; Something that gets you mixed up; Something mysterious.

\section{Curiosity Scale}

Something you would like to study; Something that you would like to figure out; Something you would like to see a movie about; Something that you wonder about; Something that you would like to understand better; Something that you would like to learn more about; Something you would like to read a book about; Something that you would like to have explained to you; Something that makes you curious; Something that you want to ask questions about; Something you would like to have someone tell you about; Something that makes you scratch your head and think.

\section{Goal-Relatedness Scale}

Money; something you can buy things with; Something that you can save in a piggy bank; A weekly allowance; Something that is worth a lot; Something you can use to get toys.

\section{RESULTS}

The number of statements of each type that were attributed to each of the four syllables was tallied. On the scales that were comprised of both positive and negative poles (pleasantness and understandability), a difference score was found for each syllable representing the

Table 1

\begin{tabular}{|c|c|c|c|c|}
\hline Scale & $\begin{array}{c}\text { Rewarded } \\
\text { (W) }\end{array}$ & $\begin{array}{l}\text { Non- } \\
\text { Rewarded } \\
(\mathrm{O})\end{array}$ & $\begin{array}{c}\text { Neutral } \\
(\mathrm{N})\end{array}$ & $\begin{array}{c}\text { Reward- } \\
\text { Loss } \\
\text { (L) }\end{array}$ \\
\hline Pleasantness & 1.57 & -.12 & -.35 & -1.05 \\
\hline Understandability & .92 & .30 & -.60 & -.62 \\
\hline Curiosity & 2.87 & 2.70 & 3.25 & 3.12 \\
\hline Goal-relatedness & 2.85 & 1.35 & 1.05 & .75 \\
\hline
\end{tabular}

number of positive statements minus the number of negative statements.

An analysis of variance was performed on the scores for each syllable under each scale comparing the boy-form with the word-form. The only significant differences between the two forms occurred on the goal object scale scores for the winning and losing syllables. The boy-form produced more goal-related responses to the winning syllable than did the word-form: $F(1,38)=6.86(p<.05)$. The word-form produced more goal-related responses to the losing syllable than did the word-form: $F(1,38)=7.83(p<.01)$.

Table 1 shows the mean ratings of the four syllables on each of the semantic appraisal scales. The results concerning ratings of the syllables on each scale of the semantic appraisal measure will be presented individually.

\section{Pleasantness Scale}

An analysis of variance applied to the ratings of the syllables yielded: $F(3,117)=12.07, \quad p<.01$. Subsequent Newman-Keuls comparisons revealed that the $W$ was rated significantly higher in pleasantness than the $0, N$, and $L$ $(p<.01)$.

\section{Understandability Scale}

An analysis of variance on the understandability ratings yielded: $F(3,117)=9.27, p<.01$. Newman-Keuls comparisons showed that the $W$ was rated significantly higher than the $\mathrm{N}$ and $\mathrm{L}$ $(\mathrm{p}<.05)$.

\section{Curiosity Scale}

An analysis of variance revealed that the four syllables were rated similarly on the curiosity scale.

\section{Goal-Relatedness Scale}

An analysis of variance on the goal-relatedness of the syllables yielded: $F(3,117)=9.01 \quad(p<.01) . \quad$ Subsequent Newman-Keuls comparisons showed that the $W$ was rated significantly more goal-related than the $0, N$, and $L(p<.01)$.

A correlation ratio was calculated for each semantic scale by obtaining the square root of the quantity (variance of means/total variance). The following ratios resulted: pleasantness $=.486$; understandability $=.438 ;$ curiosity $=.165$, and goal-relatedness $=.433$.

\section{DISCUSSION}

Other than for the use of a new measure of semantic appraisal, we have conducted essentially the same experiment numerous times. Consequently, what are important to consider are (1) how cleanly the different syllables were differentiated from one another by the measure of semantic appraisal, and (2) to what extent the four scales provide differential information about the experimental treatments. The former consideration is evidenced in the correlation ratios for the scales, which, except for the curiosity scale, are reasonably satisfactory. Regarding the second consideration, some examples of differential information provided by the four scales are as follows. Whereas the reward-loss syllable is appreciably below the nonrewarded syllable on the understandability scale, the two have undifferentiated means on the goal-relatedness scale. Whereas the nonrewarded and neutral syllables have very similar means on the pleasantness scale, they are well separated on the understandability scale.

If the new scales of semantic appraisal are highly useful in studies concerning the association of neutral objects with pleasant and unpleasant events, that usefulness will be attested to only in more subtle investigations than the one reported here. For example, in comparison to a syllable associated with reward on a fixed-ratio schedule, it is predicted that a randomly rewarded syllable would be responded to as less understandable and more curious, but not necessarily less pleasant or less related to goal objects. As another example, in comparison to a syllable that appears incidentally in the presence of rewards, a syllable that acts as a discriminative stimulus for the receipt of rewards will be responded to as more goal related, but not necessarily responded to as different on the other three scales. Continual refinements and extensions of scales of semantic appraisal should provide useful tools for the investigation of secondary rewards in humans.

\section{REFERENCES}

KENDALL, K. A., \& NUNNALLY, J. C. Effects of reward schedules on the acquisition of conditioned reward value. Psychonomic Science, 1968, 12, 239-240.

NUNNALLY, J. C., DUCHNOWSKI, A. J., \& KNOTT, P. D. Association of neutral objects with rewards: Effects of massed versus distributed practice, delay of testing, age and sex. Journal of Experimental Child Psychology, 1967, 5, 152-163. 
NUNNALLY, J. C. DLCHNOWSK1, A. J., \& PARKER, R. K. Association of neutral objects with rewards: Fiffect on verbal evaluation, reward expectancy and selective attention. Journal of Personality \& Social Psychology, $1965,1,270-274$.

NUNNALLY, J. C, \& FAW, T. T. The acquisition of reward value in discrimination leaming. Child Development, 1968, 39 , 159-166.

NUNNALLY, J. C., STEVENS, D. A., \& HALL, G. F. Association of neutral objects with rewards: Effect on verbal evaluation and eye movements. Journal of Experimental Child Psychology, 1965, 2, 44-57.

PARKER, R. K., \& NUNNALLY, J, C. Association of neutral objects with rewards: Effects of reward schedules on reward expectancy, verbal evaluation and selective attention. Journal of Experimental Child Psychology, 1966, 3, 324-332.
NOTES

1. While this research was in progress, the first author was receiving stipend suppert from PHS Training Grant No. MH08528 from the National Institute of Mental Health to the Department of Psychology. The study also was supported, in part, by a research grant from the National Institute of Child Health and Human Development, No.HD03083, to the second author.

2. Duchnowski, A. J., Nunnally, I. C., and Faw, T. T. Acquired reward value in discrimination learning: Methodological developments and effects of reward magnitude and reward schedules. In preparation.

3. The authors wish to express their appreciation to Dr. Ed Binkley, Director of the Division of Educational Research for Metropolitan Nashville Public Schools, Mrs. James Cannon of Andrew Jackson School, and Mr. Willie Nixon of Glengarry School for their cooperation and assistance in making subjects available. of detail in pictorial stimuli might affect the size of obtained picture-word differences. In the present study, concrete nouns, simple line drawings, and color photographs were compared as stimulus items. Photographs were chosen to be as rich in detail as possible, and line drawings were constructed to be as barren as possible of incidental detail, consistent with the requirement that both could be easily labeled with the corresponding concrete noun. More recall was predicted with color photographs than with line drawings (which have been more often employed in picture-word comparisons). Also, postexperimental questionnaires were given to determine whether or not the two types of pictorial stimuli differed in reported use of mnemonic aids to mediate associations.

\section{METHOD}

All Ss learned a list of 20 paired-associates by the study-test procedure. In the word group, Ss were presented 20 pairs of concrete nouns. The 40 nouns were chosen to achieve minimum interitem association and a broad range of Thorndike-Lorge frequency. They were paired randomly. The same pairs were used in drawing and photograph groups, except that stimulus nouns were replaced by simple line drawings and by color photographs, respectively. Informal pilot data indicated that drawings and photographs were nearly always labeled by the noun they replaced.

Pairs and test stimuli were presented manually on white $5 \times 8$ cards. A nonsystematically different order of presentation was used on each trial. All Ss performed to a criterion of one perfect trial or to completion of nine trials. Responses were given orally by $S$ and recorded on an answer sheet by $\mathbf{E}$. Cards were presented for $2.5 \mathrm{sec}$ on study trials and $5 \mathrm{sec}$ on test trials; each exposure accompanied the clicking of an electric timer. An intertrial interval of approximately $30 \mathrm{sec}$ was employed.

After reaching criterion, Ss in drawing and photograph groups were asked to label the stimuli. They were then given a sheet that presented the 20 pairs with space in which they were to write a brief description of any "mnemonic devices or memory tricks" they may have used to learn each pair. Examples of the use of imagery and verbal mediation were given with these instructions. For pairs learned without any mediational device, they were asked to write the word "rote."

The Ss were 63 introductory psychology students at Pennsylvania State University who participated for class credit. They were tested individually and were assigned nonsystematically to one of the three 